\title{
SIGMA: A System for Integrative Genomic Microarray Analysis of
} Cancer Genomes

\author{
Raj Chari*1,3, William W Lockwood ${ }^{1}$, Bradley P Coe ${ }^{1}$, Anna Chu ${ }^{1}$, \\ Devon Macey ${ }^{1}$, Andrew Thomson ${ }^{1}$, Jonathan J Davies ${ }^{1}$, Calum MacAulay ${ }^{2}$ \\ and Wan L Lam ${ }^{1}$
}

\begin{abstract}
Address: ${ }^{1}$ Department of Cancer Genetics and Developmental Biology, British Columbia Cancer Research Centre, Vancouver, BC, Canada, ${ }^{2}$ Department of Cancer Imaging, British Columbia Cancer Research Centre, Vancouver, BC, Canada and ${ }^{3}$ BC Cancer Research Centre, 675 West 10th Avenue, Vancouver, BC, V5Z 1L3, Canada

Email: Raj Chari* - rchari@bccrc.ca; William W Lockwood - wlockwood@bccrc.ca; Bradley P Coe - bcoe@bccrc.ca; Anna Chu - achu@bccrc.ca; Devon Macey - dmacey@bccrc.ca; Andrew Thomson - athomson@bccrc.ca; Jonathan J Davies - jdavies@bccrc.ca;

Calum MacAulay - cmacaula@bccrc.ca; Wan L Lam - wanlam@bccrc.ca

* Corresponding author
\end{abstract}

Published: 27 December 2006

BMC Genomics 2006, 7:324 doi:10.1/86//47/-2164-7-324
Received: 26 November 2006

Accepted: 27 December 2006

This article is available from: http://www.biomedcentral.com/I47/-2/64/7/324

(c) 2006 Chari et al; licensee BioMed Central Ltd.

This is an Open Access article distributed under the terms of the Creative Commons Attribution License (http://creativecommons.org/licenses/by/2.0), which permits unrestricted use, distribution, and reproduction in any medium, provided the original work is properly cited.

\begin{abstract}
Background: The prevalence of high resolution profiling of genomes has created a need for the integrative analysis of information generated from multiple methodologies and platforms. Although the majority of data in the public domain are gene expression profiles, and expression analysis software are available, the increase of array CGH studies has enabled integration of high throughput genomic and gene expression datasets. However, tools for direct mining and analysis of array CGH data are limited. Hence, there is a great need for analytical and display software tailored to cross platform integrative analysis of cancer genomes.
\end{abstract}

Results: We have created a user-friendly java application to facilitate sophisticated visualization and analysis such as cross-tumor and cross-platform comparisons. To demonstrate the utility of this software, we assembled array CGH data representing Affymetrix SNP chip, Stanford cDNA arrays and whole genome tiling path array platforms for cross comparison. This cancer genome database contains 267 profiles from commonly used cancer cell lines representing 14 different tissue types.

Conclusion: In this study we have developed an application for the visualization and analysis of data from high resolution array CGH platforms that can be adapted for analysis of multiple types of high throughput genomic datasets. Furthermore, we invite researchers using array CGH technology to deposit both their raw and processed data, as this will be a continually expanding database of cancer genomes. This publicly available resource, the System for Integrative Genomic Microarray Analysis (SIGMA) of cancer genomes, can be accessed at http://sigma.bccrc.ca. 


\section{Background}

Array comparative genomic hybridization (CGH) is a method used to detect segmental DNA copy number alterations and is widely used to discover chromosomal aberrations in cancer and other genetic diseases $[1,2]$. In this method, differentially labeled genomic DNA samples are competitively hybridized to chromosomal targets, and the copy number balance between the two samples is reflected by their signal intensity ratio. Numerous array CGH platforms exist; these vary in the type of elements present on the array and their corresponding coverage of the human genome. With the development of high resolution, genome wide arrays, tens of thousands of loci can be evaluated for copy number status, facilitating the high throughput search for genes potentially involved in pathogenesis. This has allowed the identification of discrete regions of alteration that may have been missed by traditional cytogenetic methods and has proven to be a useful platform for exploring the underlying genetic basis of cancer $[1,3]$.

With the increasing utilization of array CGH, it has not only become important to establish standards for data deposition, but to develop tools to facilitate public access and to ease mining of available data. Currently, the National Center for Biotechnology Information (NCBI) Gene Expression Omnibus (GEO) repository [4] and European Bioinformatics Institute (EBI) ArrayExpress [5] provide storage for array CGH data, but these databases have been largely designed for gene expression microarrays. Although these sites support visualization of previously analyzed gene expression profiles, there are limited tools available for direct mining and analysis of array CGH data. Hence, there is a need for forums specific to array CGH data. Recently, attempts have been made in making a database primarily of lower resolution array CGH data [6]. However, with the accumulation of high density array data generated with diverse technology, the viewing of array data has become a bioinformatics challenge, especially when the integration of multiple datasets from different platforms is required. Therefore, a central database with analytical software tailored specifically for analyzing and visualizing different types of high resolution array CGH data would greatly facilitate data mining.

In this study we have created a database consisting of high-resolution, whole-genome array CGH profiles for nearly 200 commonly used cancer cell lines profiled on four different array platforms, which have been instrumental in biochemical and pharmacogenetic studies. Moreover, we have developed a user friendly, web-based java application called the System for Integrative Genomic Microarray Analysis (SIGMA) for comparative analysis of multiple genomes.

\section{Results and Discussion Cell-line collection}

We have assembled a collection of 267 array CGH profiles, representing 184 distinct cell lines profiled on at least one of the four array CGH platforms (Table 1, Table 2). Moreover, 14 different cancer tissue origins and 30 distinct cancer types are represented in this database, resulting in the assembly of a wide spectrum of genomes in this repository (Table 2) [see Additional file 1]. Significantly, 56 of the $267 \mathrm{CGH}$ profiles are unpublished raw data which is now made public.

\section{Main functionalities of SIGMA}

In order to increase the utility of this collection, a significant component of SIGMA is the web-based application which allows for the user-friendly mining of this dataset. Four major types of functionalities are offered by SIGMA: (1) interrogation of a single sample, (2) visualization and analysis of a single group of samples, (3) comparative analysis of two groups of samples, and (4) integration of data from multiple platforms (Figure 1B).

\section{Visualization and interrogation of a single genome}

The first function we discuss is the ability to view a single high resolution array CGH profile at multiple magnification levels. The major utility of this function is to display the underlying genomic architecture of a cell line, so that genetic features can be considered in experimental interpretation. For example, a whole genome karyogram of lung adenocarcinoma cell line $\mathrm{H} 2087$ profiled on the SMRT array platform (Figure 2A). From this image, we see many changes such as the loss of the $3 p$ arm as well as segmental changes in chromosomes 8,19 and 20. Specifically, we can select chromosome 8 (Figure 2B) and view that separately, then zoom into the region of interest and visualize it in finer detail (Figure 2C). Users can then highlight or place boundary lines in this region and query for which genes are located within the region of interest.

Subsequently, using the interval search option, users can retrieve the genes which are located in a desired region and have the option to query commonly used biological databases such as NCBI MIM, NCBI Gene, NCBI PubMed and the UCSC Genome Browser. For example, if we look at band 8q24.21 (Figure 2D), we can highlight the region and search the interval for which genes it contains. When we invoke the region search and retrieve only genes curated by RefSeq, we see there are 8 genes in the amplicon. If the user selects a particular gene, options to link out to the above mentioned biological databases become available. The utility of this function is to facilitate a direct connection from experimental findings to known, relevant information. Moreover, the ability to interrogate for specific genes and regions can be done for any types of the analysis outlined (Figure 1B). 
Table I: Breakdown of cell line sources by tumor type and study

\begin{tabular}{|c|c|c|c|c|c|c|}
\hline Tissue origin & Reference & $\begin{array}{c}\text { \# of } \\
\text { samples }\end{array}$ & Array Platform & $\begin{array}{l}\text { PubMed } \\
\text { ID }\end{array}$ & $\begin{array}{l}\text { Data Deposited } \\
\text { Online? }\end{array}$ & Location \\
\hline Mantle cell lymphoma & de Leeuw et al. (2004) & 8 & SMRT Array & 15229187 & Yes & $\begin{array}{l}\text { bccrc.ca/images } / \mathrm{cg} / \\
\text { wanlam_mcl_sd.txt }\end{array}$ \\
\hline Non-small cell lung cancer & Garnis et al. (2006) & 28 & SMRT Array & 16187286 & Yes & GEO: GSE2922 \\
\hline $\begin{array}{l}\text { Small cell lung cancer, } \\
\text { Lymphoblast }\end{array}$ & Coe et al.(2006a) & 21 & SMRT Array & 16130125 & No & This study² \\
\hline Breast Cancer & Shadeo et al. (2006) & 7 & SMRT Array & 16417655 & Yes & GEO: GSE3I06 \\
\hline $\mathrm{NCl}-60$ panel ${ }^{1}$ & Garraway et al. (2005) & 58 & $\begin{array}{c}\text { Affymetrix I00K SNP } \\
\text { Array }\end{array}$ & 16001072 & Yes & GEO: GSE2520 \\
\hline $\begin{array}{l}\text { Small cell lung cancer, Breast } \\
\text { cancer, Lymphoblast }\end{array}$ & Zhao et al. (2004) & 33 & Affymetrix I0K SNP Array & 15126342 & Yes & $\begin{array}{l}\text { research.dfci.harvard.edu/ } \\
\text { meyersonlab/snp/cellFile/ }\end{array}$ \\
\hline Non-small cell lung cancer & Zhao et al. (2005) & 27 & $\begin{array}{c}\text { Affymetrix } 100 \mathrm{~K} \text { SNP } \\
\text { Array }\end{array}$ & 15994928 & Yes & $\begin{array}{c}\text { research2.dfci.harvard.edu/dfci/ } \\
\text { snp/ }\end{array}$ \\
\hline Small cell lung cancer & Kim et al. (2006) & 24 & Stanford cDNA Array & 16116477 & Yes & genome-www5.stanford.edu/ \\
\hline Breast cancer & Bredel et al. (2005) & 2 & Stanford cDNA Array & $15858 \mid 40$ & Yes & genome-www5.stanford.edu/ \\
\hline Non-small cell lung cancer & Wilson et al. (2006) & 2 & MeDIP Array & 16397413 & No & This study ${ }^{2}$ \\
\hline Osteosarcoma & Lim et al. (2004) & 1 & SMRT Array & 15660435 & No & This study ${ }^{2}$ \\
\hline Assorted ${ }^{3}$ & - & 56 & SMRT Array & - & - & This study ${ }^{2}$ \\
\hline
\end{tabular}

INCl-60 panel includes 58 of the 60 total cell lines.

2This study refers to previously unavailable data now publicly available in SIGMA

${ }^{3}$ Assorted tumor types including: Non-small cell lung cancer, small cell lung cancer, osteosarcoma, melanoma, hepatocellular carcinoma, cervical cancer, breast cancer, ovarian cancer, leukemia, and multiple myeloma

\section{Multiple genome comparison and mining across tumor types}

A common research question is to look across a series of samples with common phenotype to identify recurrent genetic changes, for example comparison of lung adenocarcinomas [see Additional file 2]. With the spectrum of samples warehoused in SIGMA, such a query can be performed across multiple cancer types. For example, the alignment of a set of samples representing 8 different cancer types revealed common amplification of the MYC oncogene locus (Figure 3A), while the epidermal growth factor receptor (EGFR) locus is amplified only in a subset of samples (Figure 3B).
Recurrent alterations detected in one group of samples can be compared against those in another group, for example, the comparison of lung squamous cell carcinoma (SqCC) with cervical SqCC [see Additional file 3]. The strategy for comparison, for example the overlay of frequency plots derived from two groups of profiles, has been described elsewhere $[7,8]$.

\section{Simultaneous visualization of data from multiple platforms}

Cross platform comparison is essential to the multidimensional descriptions of a genome. Here, we have included a feature in SIGMA to allow users to view multi-

Table 2: Breakdown of cell lines based on tissue and array platform

\begin{tabular}{|c|c|c|c|c|c|c|c|}
\hline Tissue type & $\begin{array}{c}\text { Distinct Cell } \\
\text { Lines }\end{array}$ & $\begin{array}{c}\text { Total } \\
\text { Number }\end{array}$ & $\begin{array}{l}\text { BCCRC } \\
\text { SMRT }\end{array}$ & $\begin{array}{l}\text { BCCRC } \\
\text { MEDIP }\end{array}$ & $\begin{array}{l}\text { Affymetrix } \\
\text { I00K }\end{array}$ & $\begin{array}{l}\text { Affymetrix } \\
\text { I0K }\end{array}$ & $\begin{array}{l}\text { Stanford } \\
\text { cDNA }\end{array}$ \\
\hline Lung & 74 & 123 & 54 & 2 & 36 & 7 & 24 \\
\hline Breast & 22 & 37 & 17 & 0 & 7 & 11 & 2 \\
\hline Colon & 8 & 9 & 2 & 0 & 7 & 0 & 0 \\
\hline Lymphoma & 10 & 10 & 9 & 0 & I & 0 & 0 \\
\hline Leukemia & 4 & 6 & 2 & 0 & 4 & 0 & 0 \\
\hline Brain/CNS & 6 & 6 & 0 & 0 & 6 & 0 & 0 \\
\hline Lymphoblast' & 20 & 31 & 16 & 0 & 0 & 15 & 0 \\
\hline Kidney & 7 & 7 & 0 & 0 & 7 & 0 & 0 \\
\hline Skin & 11 & 12 & 4 & 0 & 8 & 0 & 0 \\
\hline Cervix & 8 & 8 & 8 & 0 & 0 & 0 & 0 \\
\hline Ovary & 7 & 8 & 2 & 0 & 6 & 0 & 0 \\
\hline Prostate & 3 & 5 & 3 & 0 & 2 & 0 & 0 \\
\hline Liver & I & I & I & 0 & 0 & 0 & 0 \\
\hline Bone & 2 & 2 & 2 & 0 & 0 & 0 & 0 \\
\hline Bone Marrow & 1 & 2 & 1 & 0 & 1 & 0 & 0 \\
\hline Grand Totals & 184 & 267 & 121 & 2 & 85 & 33 & 26 \\
\hline
\end{tabular}

'Normal lymphoblast lines derived from patients with tumors 
A

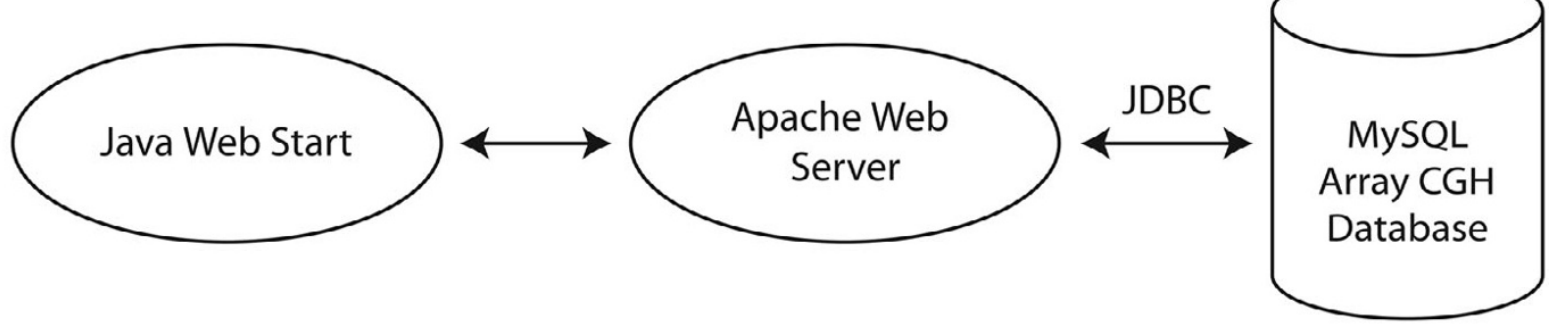

B

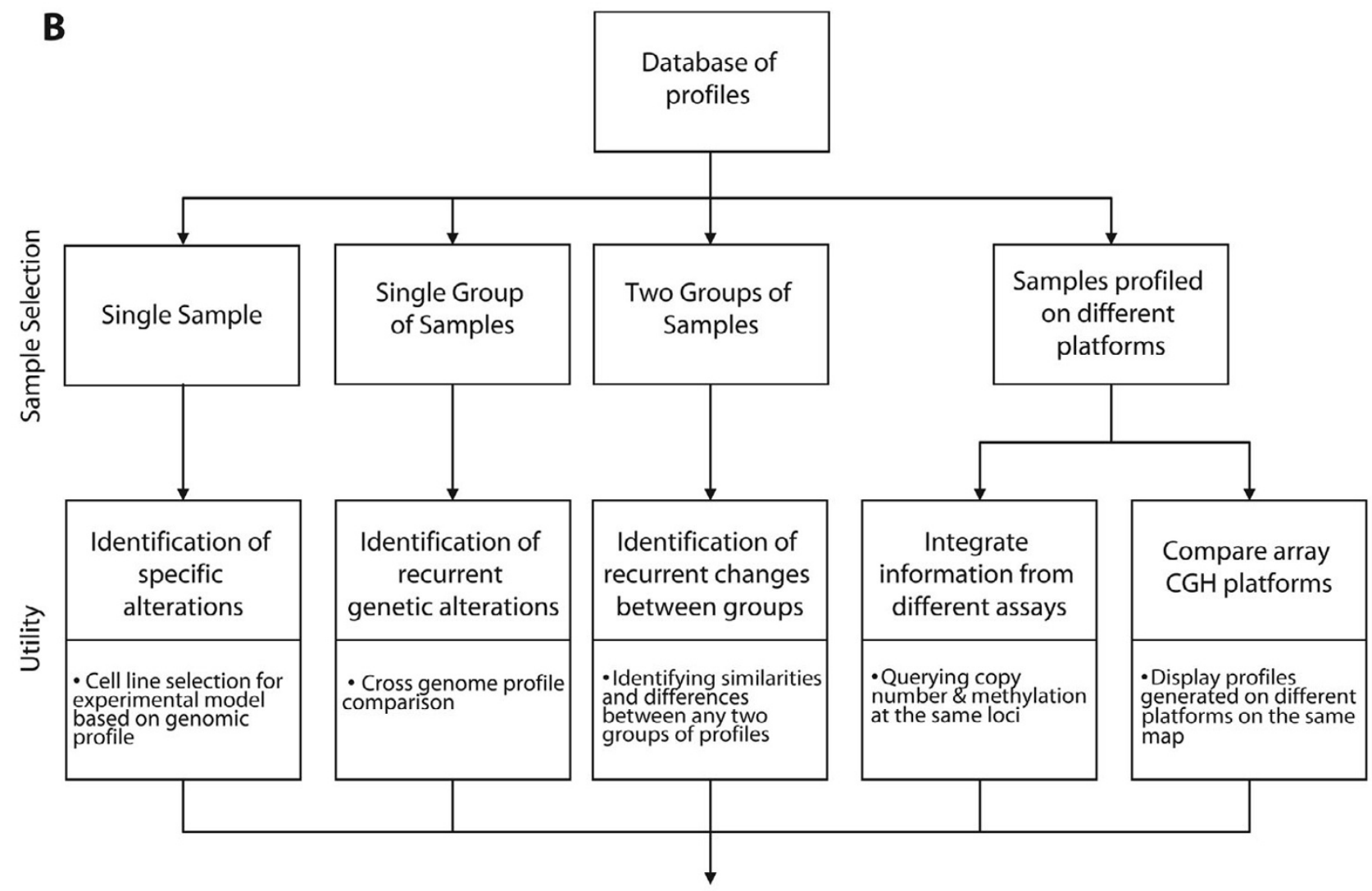

Linking to

biological

databases

Figure I

(A) Schematic of the basic architecture of SIGMA. Java WebStart technology was utilized to develop the main user interface to the database, ensuring users will be running the latest version of the program. The application is connected to the MySQL database through a JDBC driver provided by MySQL, over an Apache Web Server. (B) Outline of the various functionalities of SIGMA, with the five main types of visualization and analysis along with their associated uses.

ple platforms of data simultaneously. We use the breast cancer cell line, MCF7, to illustrate this functionality. Data from four different array CGH platforms were available publicly: SMRT array, Stanford cDNA microarray, Affyme- trix 10K SNP array and the Affymetrix 100K SNP array. Figure 4A illustrates the cross platform display of chromosome 17 , while Figure $4 \mathrm{~B}$ shows the variable density of coverage by these four commonly used platforms. 
A

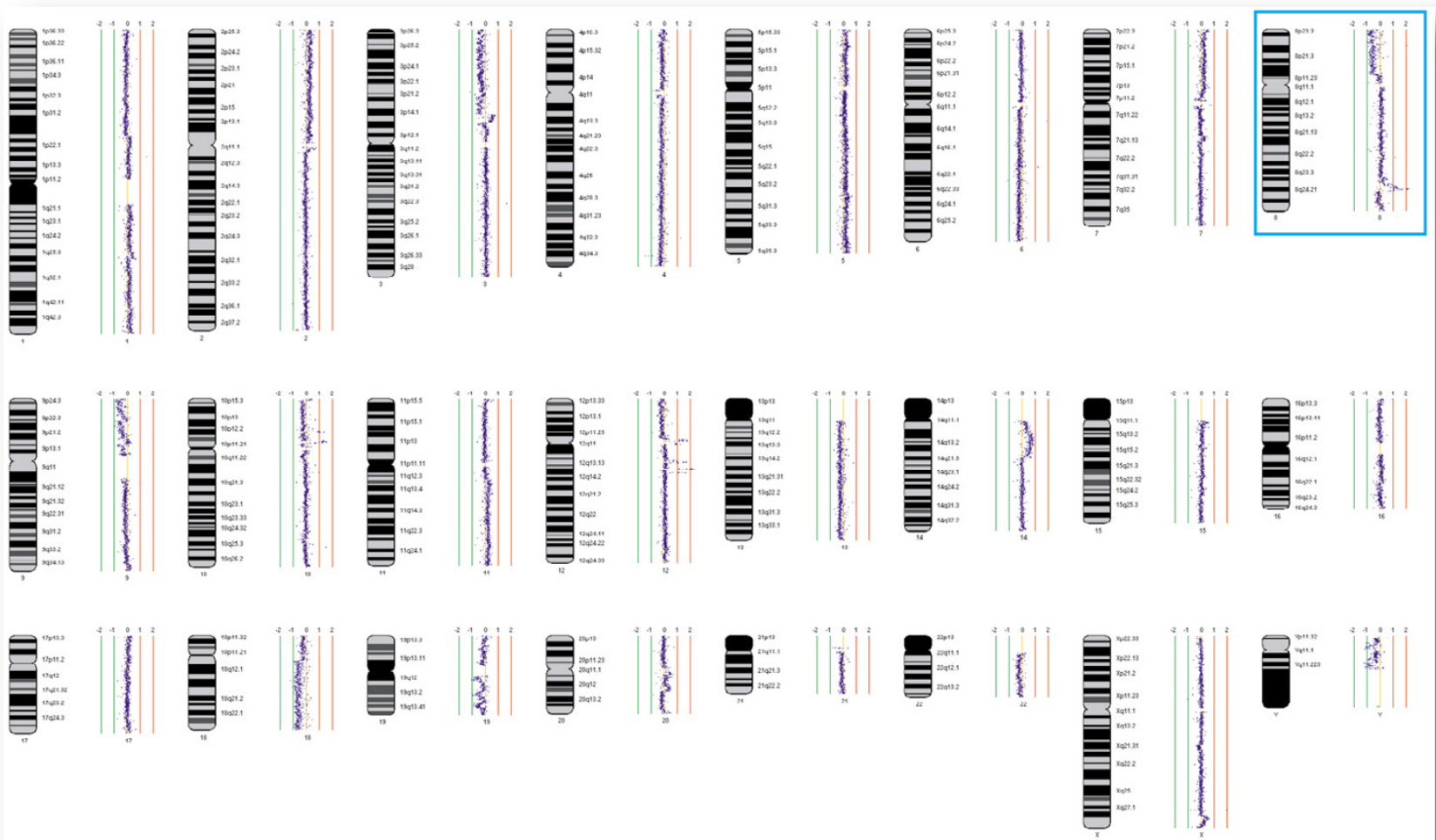

B

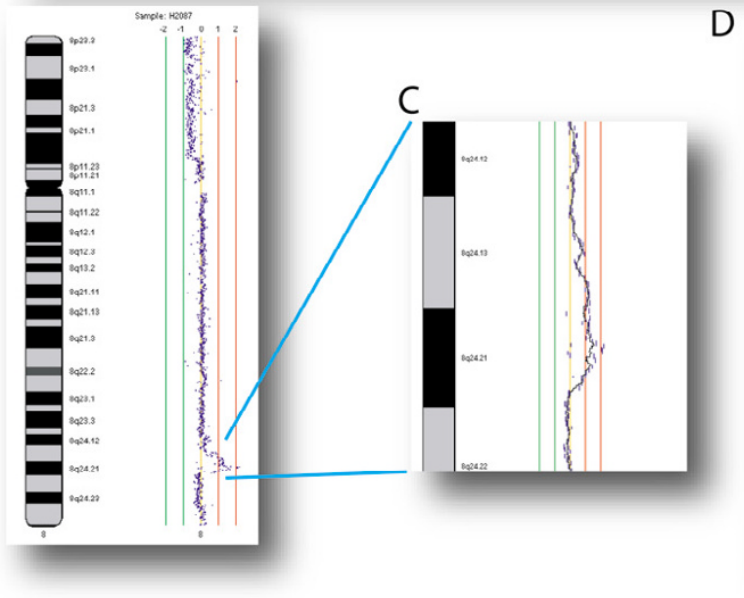

D

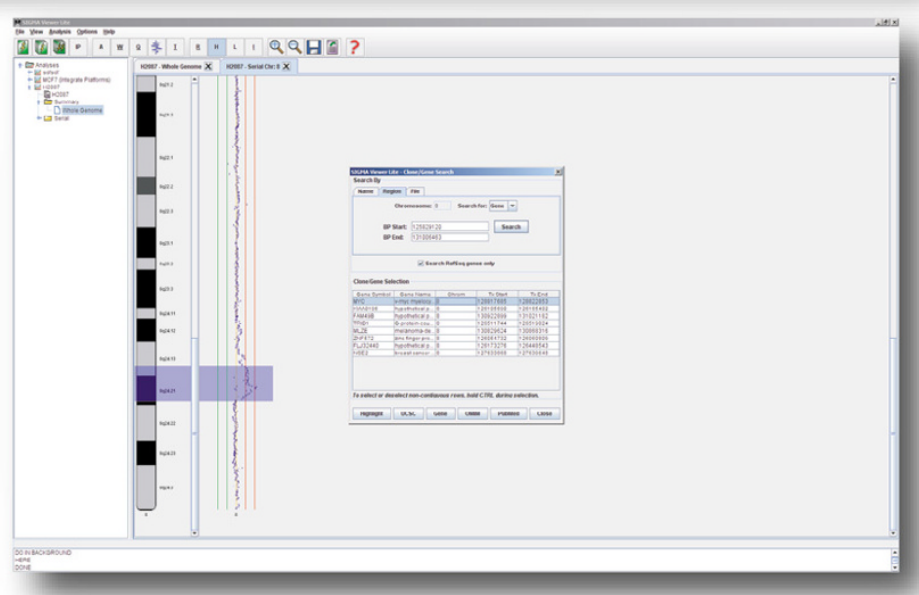

\section{Figure 2}

(A) Whole genome karyogram of the H2087 lung adenocarcinoma cell line profiled on the SMRT array using the May 2004 genomic build. For each chromosome, there is a ratio plot associated with plotting the $\log _{2}$ ratio of the genomic element vs. the position of the element on the chromosome. The $\log _{2}$ ratio of the data point is calculated against a normal reference where positive ratios represent increased content and negative ratios represent decreased content in the tumor compared to the normal. (B) The first level of zoom to view a particular chromosome, in this case, chromosome 8 . (C) $32 X$ zoom into the amplicon at chromosome band 8q24.2I. (D) The ability to link out to biological databases such as NCBI MIM, UCSC Genome Browser, NCBI Gene and NCBI PubMed with a gene of interest.

\section{Integrative visualization of DNA copy number and methylation}

One of the novel features we have provided is the integrative visualization of copy number alterations with DNA methylation status. The major premise in studying copy number alterations at the DNA level is that these are the primary changes involved in driving changes in gene expression. Though gene dosage variation may be respon- 


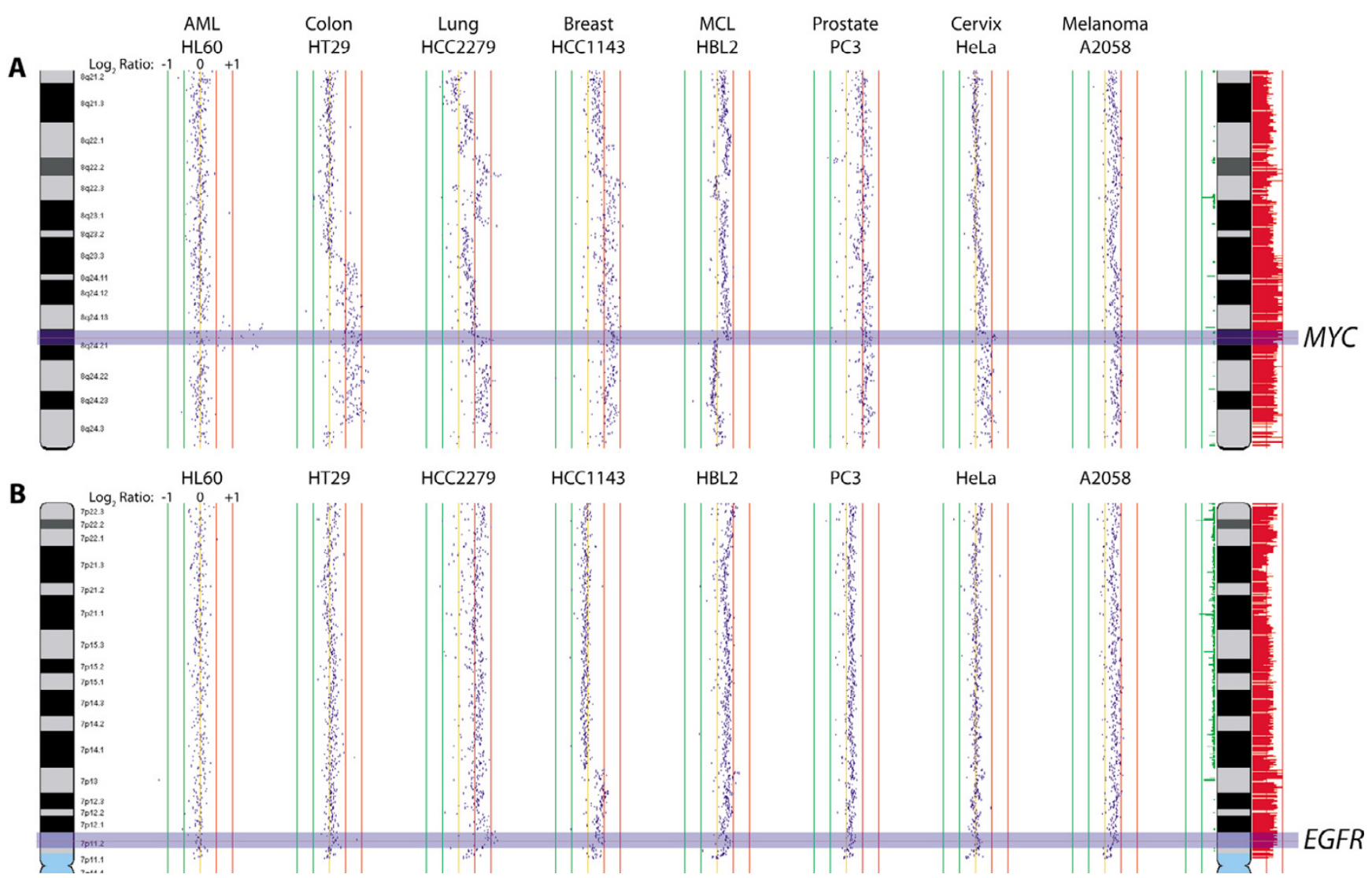

Figure 3

Serial view of 8 samples representing 8 different tumor types, demonstrating the breadth of data available. From left to right: HL60, HT29, HCC2279, HCCI I43, HBL2, PC3, HeLa and A2058. (A) Chromosome 8, highlighting the amplification of the MYC oncogene, which appears to be amplified in all 8 tumor types. (B) Chromosome 7, highlighting the EGFR locus, where it appears that the lung cancer line $(\mathrm{HCC} 2279)$ and the breast cancer line $(\mathrm{HCCl} / 43)$ harbor the amplification of this gene. Vertical lines denote $\log _{2}$ signal ratios from $-I$ to $+I$ with copy number increases to the right and decreases to the left of 0 . Each black dot represents a single BAC clone.

sible for expression changes, alteration in DNA methylation pattern also contributes significantly to regulating gene expression. Recently, methods for global methylation analysis to measure aberrant DNA methylation status across tumor genomes have been developed [9-12]. Wilson et al (2006) compared methylation patterns with copy number profiles in lung cancer cells. Utilizing genomic and epigenetic data from this study for the H1395 lung cancer cell line, we illustrate a parallel display in SIGMA. Figure 5 shows a large segmental copy number gain spanning 1q21.2 to 1q23.1 with corresponding hypomethylation, localized precisely to 1q21.3 [13]. Significantly, both copy number gain and decreased methylation can elevate gene expression. The $S 100$ calcium binding protein A10 (S100A10) gene within this region has been previously shown to be over-expressed in lung cancer [14]. It is readily apparent of the value of integrative studies examining aberrant DNA methylation and genomic copy number.
With increased prevalence of studies of whole genome methylation, this feature will be of greater importance.

\section{Conclusion}

We have developed an application for the integrative cross platform analysis of array CGH data. The SIGMA application facilitates consolidation and structuring of diverse sources of array CGH data into a repository that is accessible with a new easy-to-use built-in web-based analytical application. The launch version contains data for 267 array CGH profiles, representing cancer cell lines of over 14 different types of tissue. The ability of SIGMA to incorporate multiple array $\mathrm{CGH}$ platforms facilitates the archiving of array CGH data from future publications, regardless of current or future array platform used. Though currently SIGMA's architecture facilitates the direct mining of genomic and epigenomic data, this can be easily adapted, and not limited to, high resolution genetic and gene expression surveys. 
A

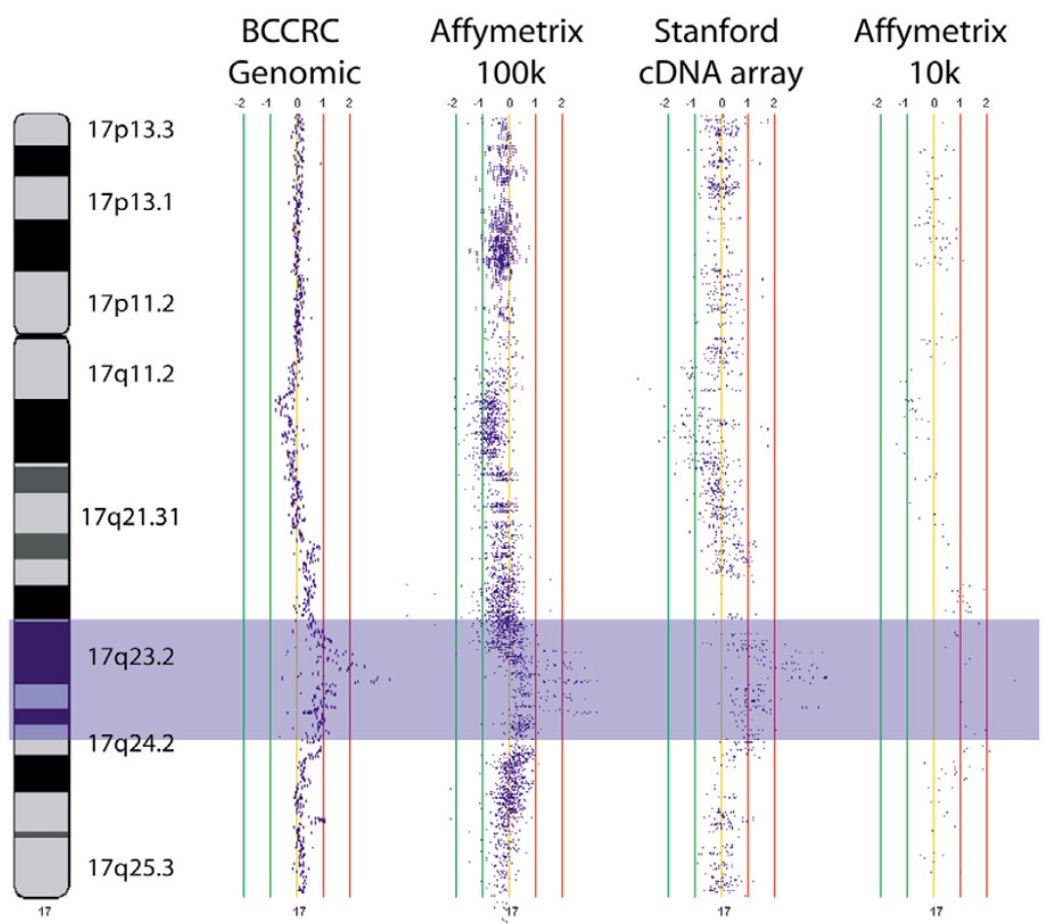

B

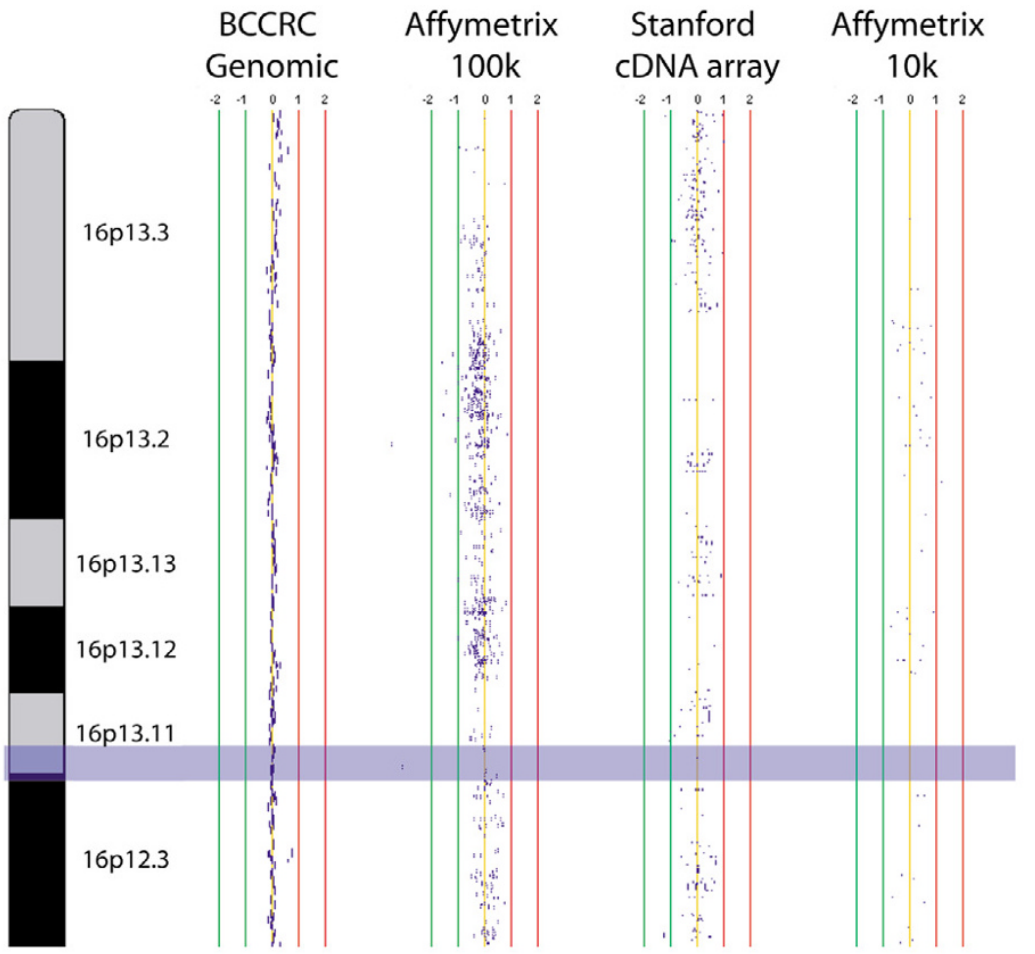

\section{Figure 4}

(A) Visualization of chromosome 17 of the breast cancer cell line MCF7 across multiple array CGH platforms using the May 2004 genomic build. The four platforms are labeled above each ratio plot. The architecture of the chromosome is consistent across all four platforms, with the altered region highlighted in yellow seen clearly across 3 of the 4 platforms. (B) Visualization of chromosome 16 of the same breast cancer cell line, illustrating decreased density of markers in 3 of the 4 array platforms, with the SMRT array providing greater coverage to a region centromeric to band $16 \mathrm{pl} 3.1 \mathrm{I}$. 


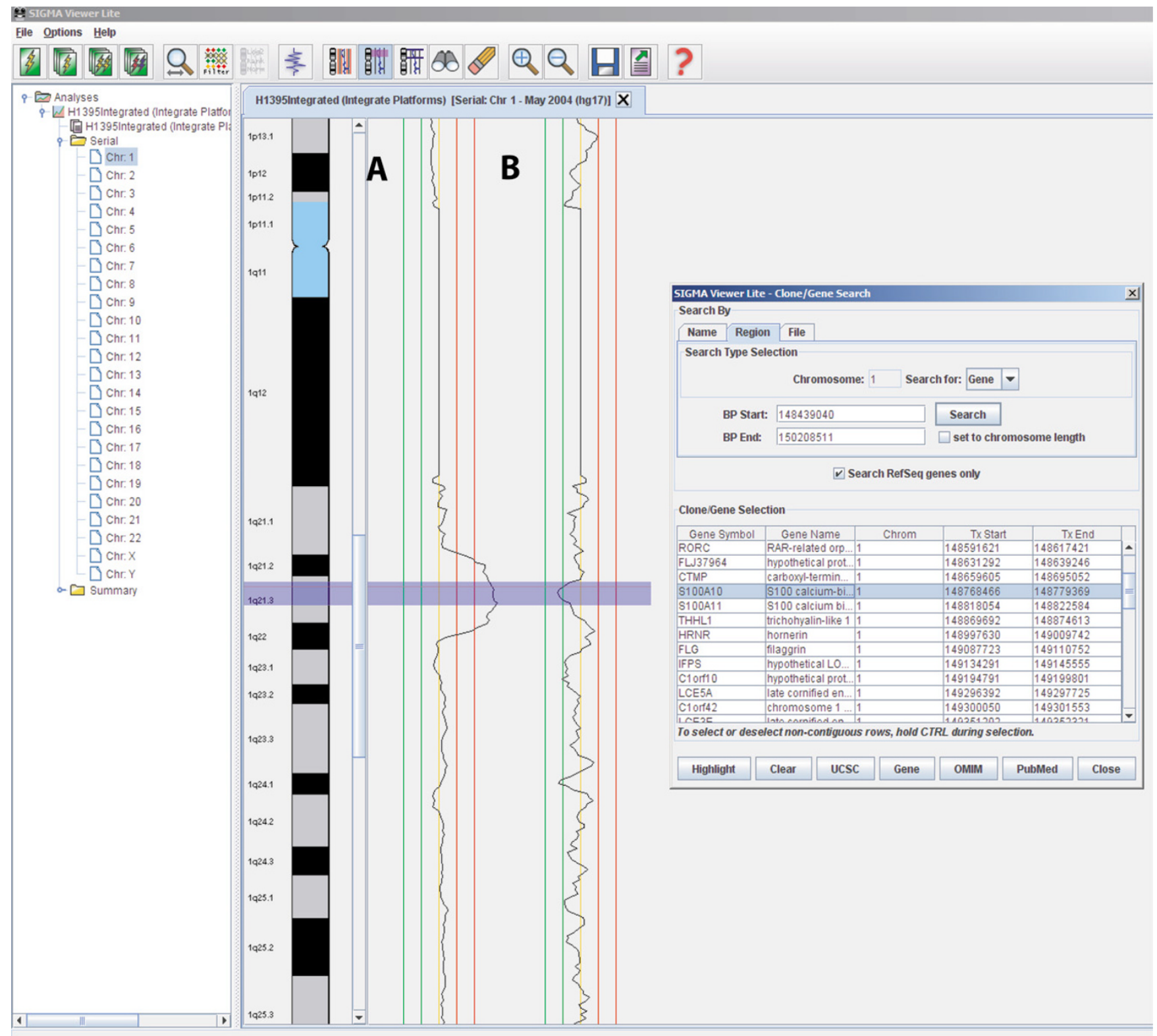

\section{Figure 5}

Integration of genomic and epigenetic profiles of the HI395 lung cancer cell line. (A) The genomic profile of HI 395 is represented by a moving average spline of the data points. (B) Similarly, the epigenetic profile represents a residual plot of the tumor cell line subtracting the matching blood lymphocyte profile (BL I395), with a moving average spline representing the data points. The moving average was done at I MB intervals at increments of $200 \mathrm{~kb}$ for both profiles. Specifically, chromosomal region Iq2 I.3 is highlighted illustrating a region of both copy number increase and hypomethylation.

\section{Methods}

\section{Sources of raw array CGH data}

The raw data for 267 CGH profiles in the database was obtained from a variety of sources. They include both published and unpublished data [7,8,15-22]. Publicly available data were downloaded from NCBI GEO [4], Stanford Microarray Database [23] or websites affiliated with the author's laboratory. Data which were not pub- licly available were obtained by consent from the authors of the respective studies. The four array CGH platforms used for this study were the whole genome tiling path BAC (SMRT) array [24], the early access Affymetrix SNP $100 \mathrm{~K}$ array $[16,20]$, the Stanford cDNA microarray [22] and the Affymetrix SNP $10 \mathrm{~K}$ array [15]. In addition, 2 of the cell lines were profiled for whole genome DNA methylation status using MeDIP array CGH $[10,13]$. For this 
launch version, we concentrated on available cell lines profiled on high density array platforms and did not include profiles from clinical specimens. A summary of the sources for the raw data is given in Table 1, while the detailed description of each of the cell lines in the collection is given in Additional file 1.

\section{Application layout of SIGMA}

There are three main components which comprise this application; a Java WebStart application interface allowing users to formulate queries and perform visualization, an Apache Web Service which facilitates the connection of the user application to the database and a relational database which is implemented using $M \gamma S Q L$ (Figure 1A). Utilization of the Java WebStart technology ensures that users will have the latest version of the application, without the need for manual updating. In addition, efficiency and speed of the application will largely be determined by the user's computer specifications. Hence, we have provided different versions of our application based on system resource utilization, allowing users with greater system resources to perform more analytical tasks per session.

\section{Database implementation and structure}

SIGMA is a continually expanding database of array CGH experiments. The launch version contains 267 genomic profiles generated from cancer cell lines, implemented using the MySQL relational database application. Each array CGH experiment is contained in a separate database table allowing for easy and seamless expansion of this database. Upon addition of a new profile, a database table which contains the information of each array CGH experiment is updated. This table stores a record of each experiment, with the name of the cell line, the American Type Culture Collection (ATCC) identification (if applicable), array platform used and the description of the cancer type as part of the schema. For two channel array-based profiles, the dye which was used to label the sample is also recorded. Lastly, mapping information pertaining to a clone or probe and its position in the genome is kept in file with a fixed format, such that subsequent improvements and updates to the genomic positioning of the array elements can be easily incorporated. Moreover, since individual microarray software platforms use their own map version, map information for all platforms were compiled based on data from the UCSC Genome Browser [25]. Currently, two genomic builds are supported: April 2003 (hg15) and May 2004 (hg17) assemblies.

\section{Data processing}

Data for each platform were processed as similarly as possible. SMRT array data were normalized using the stepwise framework for normalization with default parameters [26]. Similarly, Affymetrix $10 \mathrm{~K}$ and Affymetrix $100 \mathrm{~K}$ data were normalized and processed using dChip [27] with default settings. Specifically, the samples from the Affymetrix $10 \mathrm{~K}$ dataset of lung cancer cell lines were referenced against the group of matching blood lymphoblast lines and similarly, the breast cancer cell lines were referenced against their matching blood lymphoblast lines. Affymetrix $100 \mathrm{~K}$ data from Zhao et al. (2004) were referenced against 12 normal individuals and the NCI-60 profiles were referenced against 6 normal diploid controls. The gender of the profiles were not specified, hence data from the $\mathrm{X}$ chromosome may not be an accurate reflection. Segmentation of all data was performed using aCGH-Smooth [28], with data for the sex chromosomes removed prior to segmentation - as profiles were generated with sex matched or mismatched reference DNA in two channel hybridization experiments - and run with the settings of Lambda $=6.75$ and "breakpoints per chromosome" = 100. Each element of the array is given a call with respect to normal: -1 if the element shows copy loss, 0 if the element shows no change in copy number and +1 if the element shows increased genomic content.

\section{Abbreviations}

SIGMA: System for Integrative Genomic Microarray Analysis

\section{CGH: Comparative Genomic Hybridization}

SNP: Single Nucleotide Polymorphism

\section{Availability and requirements}

Project name: SIGMA (System for Integrative Genomic Microarray Analysis)

Project home page: http://sigma.bccrc.ca

Operating system(s): Platform independent

Programming language: Java

Other requirements: Java version 1.6+

License: Free for academic and research use, commercial users please request special permission

\section{Authors' contributions}

RC designed and developed SIGMA and wrote the manuscript. WWL and BPC were involved in the design and development. AC, DM and AT were the programmers. JJD was involved with initial design and CM provided manuscript editing and program feedback. WLL is the principal investigator of the lab. 


\section{Additional material}

\section{Additional file 1}

List of cell lines in database. Detailed description of all the cell lines. Click here for file

[http://www.biomedcentral.com/content/supplementary/14712164-7-324-S1.xls]

\section{Additional file 2}

Single group visualization. Whole genome frequency plot of lung adenocarcinoma

Click here for file

[http://www.biomedcentral.com/content/supplementary/14712164-7-324-S2.pdf]

\section{Additional file 3}

Two group whole genome comparison. Whole genome frequency plot comparison of squamous cancer of the lung and cervix.

Click here for file

[http://www.biomedcentral.com/content/supplementary/14712164-7-324-S3.pdf]

\section{Acknowledgements}

We thank lan Wilson for useful discussion and Byron Cline for extensive testing of the application as well as Andrew Lam for tutorial development. This work was supported by funds from Genome Canada/Genome British Columbia, Canadian Institute of Health Research, and NIDCR grant ROI DEI5965-0I.

\section{References}

I. Lockwood WW, Chari R, Chi B, Lam WL: Recent advances in array comparative genomic hybridization technologies and their applications in human genetics. Eur J Hum Genet 2006, | 4(2): | 39- 148.

2. Davies JJ, Wilson IM, Lam WL: Array CGH technologies and their applications to cancer genomes. Chromosome Res 2005, I3(3):237-248.

3. Pinkel D, Albertson DG: Array comparative genomic hybridization and its applications in cancer. Nat Genet 2005, 37 Suppl:SI I-7.

4. Barrett T, Suzek TO, Troup DB, Wilhite SE, Ngau WC, Ledoux P, Rudnev D, Lash AE, Fujibuchi W, Edgar R: NCBI GEO: mining millions of expression profiles--database and tools. Nucleic Acids Res 2005, 33(Database issue):D562-6.

5. Parkinson H, Sarkans U, Shojatalab M, Abeygunawardena N, Contrino S, Coulson R, Farne A, Lara GG, Holloway E, Kapushesky M, Lilja P, Mukherjee G, Oezcimen A, Rayner T, Rocca-Serra P, Sharma A, Sansone S, Brazma A: ArrayExpress--a public repository for microarray gene expression data at the EBI. Nucleic Acids Res 2005, 33(Database issue):D553-5.

6. La Rosa P, Viara E, Hupe P, Pierron G, Liva S, Neuvial P, Brito I, Lair S, Servant N, Robine N, Manie E, Brennetot C, Janoueix-Lerosey I, Raynal V, Gruel N, Rouveirol C, Stransky N, Stern MH, Delattre O, Aurias A, Radvanyi F, Barillot E: VAMP: visualization and analysis of array-CGH, transcriptome and other molecular profiles. Bioinformatics 2006.

7. Coe BP, Lockwood WW, Girard L, Chari R, Macaulay C, Lam S, Gazdar AF, Minna JD, Lam WL: Differential disruption of cell cycle pathways in small cell and non-small cell lung cancer. Br J Cancer 2006, 94( 1 2): I 927-1935.

8. Garnis C, Lockwood WW, Vucic E, Ge Y, Girard L, Minna JD, Gazdar AF, Lam S, Macaulay C, Lam WL: High resolution analysis of nonsmall cell lung cancer cell lines by whole genome tiling path array CGH. Int J Cancer 2006, I I 8(6): I 556-I 564.
9. Ching TT, Maunakea AK, Jun P, Hong C, Zardo G, Pinkel D, Albertson DG, Fridlyand J, Mao JH, Shchors K, Weiss WA, Costello JF: Epigenome analyses using BAC microarrays identify evolutionary conservation of tissue-specific methylation of SHANK3. Nat Genet 2005, 37(6):645-65I

10. Weber M, Davies J], Wittig D, Oakeley EJ, Haase M, Lam WL, Schubeler D: Chromosome-wide and promoter-specific analyses identify sites of differential DNA methylation in normal and transformed human cells. Nat Genet 2005, 37(8):853-862.

II. Khulan B, Thompson RF, Ye K, Fazzari MJ, Suzuki M, Stasiek E, Figueroa ME, Glass JL, Chen Q, Montagna C, Hatchwell E, Selzer RR, Richmond TA, Green RD, Melnick A, Greally JM: Comparative isoschizomer profiling of cytosine methylation: The HELP assay. Genome Res 2006.

12. Karimi M, Johansson S, Stach D, Corcoran M, Grander D, Schalling M, Bakalkin G, Lyko F, Larsson C, Ekstrom TJ: LUMA (LUminometric Methylation Assay)--a high throughput method to the analysis of genomic DNA methylation. Exp Cell Res 2006, 3 I 2(I I): I 989- I995.

13. Wilson IM, Davies J], Weber M, Brown CJ, Alvarez CE, MacAulay C, Schubeler D, Lam WL: Epigenomics: mapping the methylome. Cell Cycle 2006, 5(2): I55-I 58.

14. Remmelink M, Mijatovic T, Gustin A, Mathieu A, Rombaut K, Kiss R, Salmon I, Decaestecker C: Identification by means of cDNA microarray analyses of gene expression modifications in squamous non-small cell lung cancers as compared to normal bronchial epithelial tissue. Int J Oncol 2005, 26(I):247-258.

I5. Zhao X, Li C, Paez JG, Chin K, Janne PA, Chen TH, Girard L, Minna J, Christiani D, Leo C, Gray JW, Sellers WR, Meyerson M: An integrated view of copy number and allelic alterations in the cancer genome using single nucleotide polymorphism arrays. Cancer Res 2004, 64(9):3060-3071.

16. Garraway LA, Widlund HR, Rubin MA, Getz G, Berger AJ, Ramaswamy S, Beroukhim R, Milner DA, Granter SR, Du J, Lee C, Wagner SN, Li C, Golub TR, Rimm DL, Meyerson ML, Fisher DE, Sellers WR: Integrative genomic analyses identify MITF as a lineage survival oncogene amplified in malignant melanoma. Nature 2005, 436(7047): I | 7-I 22.

17. de Leeuw RJ, Davies J], Rosenwald A, Bebb G, Gascoyne RD, Dyer MJ, Staudt LM, Martinez-Climent JA, Lam WL: Comprehensive whole genome array CGH profiling of mantle cell lymphoma model genomes. Hum Mol Genet 2004, I 3( I 7): I 827-I837.

18. Coe BP, Lee EH, Chi B, Girard L, Minna JD, Gazdar AF, Lam S, Macaulay C, Lam WL: Gain of a region on 7 p22.3, containing MADILI, is the most frequent event in small-cell lung cancer cell lines. Genes Chromosomes Cancer 2006, 45(I): I I- I9.

19. Shadeo A, Lam WL: Comprehensive copy number profiles of breast cancer cell model genomes. Breast Cancer Res 2006 , 8(I):R9.

20. Zhao X, Weir BA, LaFramboise T, Lin M, Beroukhim R, Garraway L, Beheshti J, Lee JC, Naoki K, Richards WG, Sugarbaker D, Chen F, Rubin MA, Janne PA, Girard L, Minna J, Christiani D, Li C, Sellers WR, Meyerson M: Homozygous deletions and chromosome amplifications in human lung carcinomas revealed by single nucleotide polymorphism array analysis. Cancer Res 2005, 65(13):556|-5570.

21. Bredel M, Bredel C, Juric D, Kim Y, Vogel H, Harsh GR, Recht LD, Pollack JR, Sikic BI: Amplification of whole tumor genomes and gene-by-gene mapping of genomic aberrations from limited sources of fresh-frozen and paraffin-embedded DNA. J Mol Diagn 2005, 7(2): I71-182.

22. Kim YH, Girard L, Giacomini CP, Wang P, Hernandez-Boussard T, Tibshirani R, Minna JD, Pollack JR: Combined microarray analysis of small cell lung cancer reveals altered apoptotic balance and distinct expression signatures of MYC family gene amplification. Oncogene 2006, 25(I): I30-138.

23. Ball CA, Awad IA, Demeter I, Gollub J, Hebert JM, Hernandez-Boussard T, Jin H, Matese JC, Nitzberg M, Wymore F, Zachariah ZK, Brown PO, Sherlock G: The Stanford Microarray Database accommodates additional microarray platforms and data formats. Nucleic Acids Res 2005, 33(Database issue):D580-2.

24. Ishkanian AS, Malloff CA, Watson SK, DeLeeuw RJ, Chi B, Coe BP, Snijders A, Albertson DG, Pinkel D, Marra MA, Ling V, MacAulay C, Lam WL: A tiling resolution DNA microarray with complete coverage of the human genome. Nat Genet 2004, 36(3):299-303. 
25. Hinrichs AS, Karolchik D, Baertsch R, Barber GP, Bejerano G, Clawson $\mathrm{H}$, Diekhans M, Furey TS, Harte RA, Hsu F, Hillman-Jackson J, Kuhn RM, Pedersen JS, Pohl A, Raney BJ, Rosenbloom KR, Siepel A, Smith KE, Sugnet CW, Sultan-Qurraie A, Thomas DJ, Trumbower H, Weber RJ, Weirauch M, Zweig AS, Haussler D, Kent WJ: The UCSC Genome Browser Database: update 2006. Nucleic Acids Res 2006, 34(Database issue):D590-8.

26. Khojasteh M, Lam WL, Ward RK, Macaulay C: A stepwise framework for the normalization of array CGH data. BMC Bioinformatics 2005, 6(I):274.

27. Lin M, Wei LJ, Sellers WR, Lieberfarb M, Wong WH, Li C: dChipSNP: significance curve and clustering of SNP-array-based loss-of-heterozygosity data. Bioinformatics 2004, 20(8): $1233-1240$.

28. Jong K, Marchiori E, Meijer G, Vaart AV, Ylstra B: Breakpoint identification and smoothing of array comparative genomic hybridization data. Bioinformatics 2004, 20(18):3636-3637.

Publish with Bio Med Central and every scientist can read your work free of charge

"BioMed Central will be the most significant development for disseminating the results of biomedical research in our lifetime. "

Sir Paul Nurse, Cancer Research UK

Your research papers will be:

- available free of charge to the entire biomedical community

- peer reviewed and published immediately upon acceptance

- cited in PubMed and archived on PubMed Central

- yours - you keep the copyright

Submit your manuscript here:

http://www.biomedcentral.com/info/publishing_adv.asp
BioMedcentral 